\title{
SOBRE EL PETRARQUISMO PERUANO
}

\author{
Giovanni Meo Zilio \\ Universidad de Venecia
}

El libro de Alicia de Colombí-Monguió, Petrarquismo peruano: Diego Dávalos y Figueroa y la poesía de la "Miscelánea Austral", London, Tamesis Books Limited, 1985, págs. 217, representa el primer trabajo realmente importante dentro de la crítica davaliana (la autora lo dedica, con palabras emocionadas y emocionantes, a su compañero y maestro Luis Monguió “quien inspiró cada página": pág. 14). En efecto, como lo aclara en el Prólogo (pág. 12), la crítica davaliana se limitaba esencialmente a los estudios de Fucilla: "Los eruditos estudios de Joseph G. Fucilla nos dieron algunas de las pocas páginas útiles que se han escrito sobre la poesía de Dávalos", autor de fines del siglo xvi casi desconocido por los no especialistas, quien, sin embargo, fue "hombre a la vez representativo y excepcional en la cultura del Virreinato del Perú" (pág. 13). Entre otras cosas, precisa: "he tratado de no abusar del vocabulario crítico al uso, pero tampoco me he esforzado por evitarlo cuando la precisión de conceptos lo requeria" (ib.). Hay que reconocerle, de entrada, que ha sabido conciliar cabalmente ambas exigencias realizando un feliz equilibrio entre lo técnico (metodología y lenguaje) y lo coloquial (más inmediato y cordial). Veamos algunos ejemplos de tal coloquialidad-cordialidad.

En lo sintáctico basta observar cómo, para decir que 'es cierto que (Cilena) se casó, nos dice, con sabrosas elipsis, "Pero casarse se casó [...]" (pág. 60) ; y para decir que 'es seguro que Remón murió' dice: "Morir Remón murió [...]" (pág. 61). En lo léxico basta ver el uso de palabras familiares como intringulis ("pero la cuestión no deja de tener su intríngulis", pág. 74). En lo fraseológico el uso de sintagmas como "hacer la América" ('hacer fortuna en América'): "bien puede colegirse que este natural de Ontiveros [Juan Remón] verdaderamente había hecho la América" (pág. 
54); y más adelante: "Dávalos decidió irse al Perú a hacer la América" (pág. 35). En lo estilístico véase cómo, para decir que no está de acuerdo con la opinión de Dávalos que niega la historicidad de La Araucana de Ercilla, introduce de repente, dentro de un contexto descriptivo, el discurso directo $y$, dirigiéndose idealmente al sujeto de la contestada opinión, estalla en el contundente y elíptico sintagma conversacional: "No Dávalos" (pág. 73). Ha sabido condimentar, además, lo coloquial con una constante leve ironía que hace más agradable la lectura al animar el argumento (el cual, por lo erudito, podria resultar hasta pesado para quien no sea del oficio) confirmándonos, a la vez, que su actitud de cordial ensimismamiento con el poeta estudiado (que representa la conditio sine qua non de toda crítica) sabe casarse con aquel distacco, aquella distancia focal que también es necesaria para evitar parcialidades y deformaciones. Creo que, aparte de la formidable erudición que aparece documentada más que nada en las notas (lo cual agiliza la lectura del texto), la clave de lectura del libro (su constante estilística) es justamente esta feliz simbiosis entre el ensimismamiento (participación anímica, sin-patía) y el distacco (neutralidad anímica, a-patía). Ya sabemos que son dos actitudes no siempre fáciles de conjugar...

Si nos detenemos ahora preliminarmente en el estilema de la ironía, vemos cómo ésta puede ir dirigida, acá y allá, hacia otros críticos literarios que han tratado el asunto. A veces, es más directa, como cuando, en la pág. 12, nos informa, casi divertida, que

En una publicación reciente de las Ediciones Cátedra, Historia de la Literatura Hispanoamericana, I, Época Colonial (Madrid, 1982), puede leerse con asombro la afirmación insólita que la miscelánea Austral es un poema épico en seis cantos, lo cual es estupendamente ilustrado nada menos que con la reproducción de la primera página de la Miscelánea, donde puede leerse Colloquio Primero, su tema, y un soneto de opósitos petrarquistas, pág. 173. Supongo que tan notable afirmación debe basarse en la Defensa de Damas, la cual sf está escrita en octavas reales y seis cantos, aunque no es un poema épico ni mucho menos.

Pero, en este caso, la A. sabe glisser garbosamente, sobre el nombre del crítico en cuestión (se trata de Pedro Piñero Ramírez), sin ahorrarle la púa (pero con altura) al utilizar el eufemismo "afirmación insólita" o la antífrasis "tan notable afirmación" (la cursiva es mía).

Otras veces es más indirecta, apenas insinuada, y entonces no elude el nombre del crítico, como cuando nos dice:

Pero ya no asombrará al lector que Dávalos despliegue su consabida erudición de segunda y hasta de tercera mano. Quien haya leído este coloquio sin más aviso, puede haber pensado que efectivamente Dávalos comienza "tras 
una rápida mención del Compendio de las cosas de Horacio Rinaldi", para luego asentar su pensamiento, como pensó Luis Jaime Cisneros, sin sospechar que la mención puede ser rápida, pero la deuda larga (pág. 117);

o cuando concluye que

Esta es la médula misma de la discusión sobre poesía, y nada de ello ha nacido de elucubraciones de nuestro ecijano, de quien es mucho decir que "arriesga su propia opinión sobre el carácter especulativo de la poesía" [aquí cita de nuevo a Cisneros], puesto que traduce haciendo suya la opinión ajena (pág. 118).

Con todo, tampoco puede achacársele actitudes de parti pris contra el autorizado lingüista y filólogo peruano, puesto que, en otros pasajes, reconoce lisa y llanamente sus aciertos, como cuando, en la pág. 120, afirma que "la identidad de lo que dicen Dávalos y la anónima [está hablando del Discurso en loor de la poesia] ha sido acertadamente notada por Cisneros".

La ironía se hace más picante (pero nunca envenenada...) cuando se trata de juzgar la actitud de autores implícita o explícitamente antifeministas. Asi, por ejemplo, después de haber comentado magistralmente el soneto de Cilena, el cual figura, primero de todos, entre los poemas de alabanza que encabezan la Miscelánea Austral, agrega:

De este Parnaso peruano de la Miscelánea Austral es, sin duda, una mujer el mejor artifice. Y no creo que quepa dudar que su autor sea quien dice serlo, pero justamente por ser mujer se ha dudado del hecho, y ya alguien ha hablado de la "mixtificación de Cilena" por lo "viril" del soneto, obra que sería imposible de sospechar que por su fuerza y calidad fuera de una mujer, como tampoco puede serlo, iclaro está!, el "Discurso en loor de la Poesía", otro caso de "mixtificación" por lo menos desde Ricardo Palma. A la postre las mujeres son débiles e iletradas (pág. 67).

Aunque veladamente, su ironía se asoma también cuando el crítico es mujer. Así, en la nota correspondiente a lo antedicho, al citar a algunos críticos varones que han sostenido la cit. "mixtificación" del Discurso en loor de la Poesia, agrega:

Es curioso notar que los razonamientos implícitamente antifeministas no son necesariamente engendrados por la sensibilidad del varón, así, la profesora Dunbar Temple: "el estilo no es femenino; es erudito y demuestra una rara perfección métrica" (pág. 68).

$\mathrm{Y}$ hay casos en que la ironía va dirigida al mismo lector, con cierto dejo de complicidad festiva, bajo forma de antifrasis en relación con lo que le está diciendo. He aquí un fragmento emblemático: 
porque es sabido que ninguno de ellos [los encomenderos] podía ignorar que el declarado fundamento sobre el cual la Corona edificó la institución de la encomienda era, ¡claro estál, espiritual. Los indios estaban encomendados a Dávalos justamente para, a mayor gloria de Dios y de la Santa Madre Iglesia, salvar sus almas para la fe verdadera (pág. 74).

Pero, más frecuente y abiertamente, la ironia va dirigida al propio Dávalos (al poeta o a su persona práctica) o bien al contexto que lo involucra. Veamos algunos pasajes sintomáticos: al relatar cómo Dávalos salvó de un torrentoso río a una hermosa india que se había caído y desmayado en las aguas, nos dice:

Salió de su desmayo la señora y su "hacimiento de gracias" debe haber sido particularmente hermoso a quien tan galanamente supo arriesgar por ella salud y vida ... (pág. 40).

Y, como si no bastara la primera alusión, precisa, en la página siguiente, que «[Dávalos] Abrazado al recuerdo de la ausente [su enamorada Brasilda a la que dejó en la natal Ecija] [...] amando como siempre a Brasilda terminó por amar, moderada y pudorosamente, a la hermosura indiana». Hay más, puesto que, en la página sucesiva, agrega, ad abundantiam: «El argumento del pobre Dávalos se hace por fuerza parentético y confuso, y a la vez se declara fiel y firme amante de la siempre bienamada Brasilda, y no menos fiel si tibio enamorado de la indiana, a quien hubo de servir por largo tiempo con tanta alegría y tan celosos tormentos que la mentada tibieza resulta sospechosa de bien altas temperaturas. [...] La cosa no tenía vuelta de hoja; Dávalos, el amante modelo, le falló a sus modelos. Así que a la hora de las explicaciones necesariamente habría de tambalearle la retórica: "Delio [es decir, Dávalos]: Como mi pecho y pensamientos estavan tan justamente ocupados [con Brasilda] no le fue tan fácil [al Amor] el sujetarme como la vez primera, pero pudo hazer conmigo que amasse con un tibio y recatado amor". [...] Sirvió Dávalos a la dama por mucho tiempo, cuanto pudo y con toda fidelidad (¿que hubiera hecho de no ser tibio?); obviamente fue su amor retribuido, pues no por nada recibió esos lícitos favores y esa consiguiente alegría en el alto mar de bonanza que navegara en sus largos servicios amorosos. [...] Que la indiana era hermosa va de suyo, y que Dávalos conoció su suma de perfecciones algo más que por la reja bien se colige [...]».

Finalmente, en la pág. 43, aparece (siempre llevado con alta e imperturbable ironía) el desenlace de aquella poco ortodoxa historia de amor(es):

Tal vez cansada del celibato recalcitrante de su galán, acaso impaciente por cambiar de estado — nada de esto, claro está, dice Dávalos- esta "summa de pureza" engañó a su amante. Comenzaron las sospechas. [...] Pues, mal que le pesara a nuestro pobre amante, la ingrata no sólo vino a confirmar sus sospechas y dar razón a sus celos, sino que bien prosaicamente vino a hacerlo casándose con otro (XLI, 195 r.). Dávalos con toda su soltería a cuestas y con oportuna prudencia, prefiere no vengar la injuria (196r.). 
Así como, en los trozos citados, hemos visto la ironía aplicada esencialmente al hombre Dávalos, he aquí ahora un ejemplo de ironía aplicado al poeta Dávalos:

Así, al hablar de la virtud nos encontramos con un espléndido despliegue de epítetos que Dávalos parece haber espigado en numerosas y variadas lecturas. [...] Dávalos se esfuerza en hacer creer, tanto por las palabras de Cilena como por las propias, que le costó gran esfuerzo y cuantioso estudio el recopilar la lista de epítetos. Pues "el trabajo que en juntarlos" ha tenido nuestro ecijano se limitó a abrir el libro de Rinaldi en las páginas 39-40 (pág. 110).

$\mathrm{Si}$, de la búsqueda de una posible clave de lectura estilística de este libro formalmente tan sabroso, pasamos ahora a considerar su contenido, o mejor a sus soportes ideológicos (los que en italiano solemos llamar assi portanti dell'opera), podemos intentar algunas consideraciones esenciales.

Ante todo, vemos asomarse, acá y allá, penetrantes observaciones sicológicas que revelan en la autora su profundo y vivido conocimiento (y participación) de lo humano amén de lo literario; más aún, una copresencia de ambos que le permite calar simultáneamente en la realidad poética y la experiencia vital del mismo Dávalos en aras de aquella sin-patía a la que me he referido más arriba. Así es que, al comentar la semblanza que Dávalos hace de su hermano Tello ya fallecido, semblanza que se parece a un autorretrato ideal, la autora reflexiona como para sí :

No nos ha dejado Dávalos ningún autorretrato, pero si, como pensaba Unamuno, todos somos junto a lo que somos lo que deseamos ser, éste es auténtico retrato de lo que alguna vez se soñara el perulero. Por cierto esta arquetípica condición del gentilhombre renacentista se debió sentir en mucho limitada por la realidad cultural y social de la tierra colla. Y, sin embargo, con todas las necesarias limitaciones que la suerte impone a cada amor nuestro, acaso nada nos refleja mejor que aquello que hemos elegido amar. El de Tello es retrato y suma del ideal de Dávalos, y en este sentido, la imagen viva del Dávalos ideal (pág. 51).

Más abajo, agrega otra reflexión basada en la experiencia humana (en su personal experiencia humana) al decirnos que "Nadie puede vivir sintiéndose siempre fugitivo. Es necesario crearse una patria, y esto no puede ser sólo labor de la nostalgia" (pág. 52); concluye, volviendo a lo literario (más aún, haciendo brotar lo literario de lo humano): "En su orfandad total, Diego Dávalos ya sólo recobrará su patria por la palabra” (ib.).

Veamos ahora, a grandes rasgos, el contenido del libro. Luego del prólogo al que ya me he referido, van cuatro capítulos prevalentemente biográficos, cuya importancia radica en el hecho de que la A. los deriva directamente de la obra del mismo D. (biografía interna): 
Si bien nunca me propuse escribir una "vida y obra", el caso es que ante un autor casi desconocido, alguna consideración biográfica se imponía. Sobre la vida de Dávalos se había publicado algo, pero a la falta de datos se añadía la sobra de errores. El lector hallará aquí datos ampliados, sobre todo con testimonios del mismo Dávalos (pág. 13).

El primer capítulo (págs. 15-25) trata de cómo y por qué Dávalos emigra de la natal Écija a Perú. El segundo (págs. 29-52), de su traslado de Lima al Alto Perú (actual Bolivia), en donde se hizo minero. El tercero (págs. 5371), de su estadía en $\mathrm{La} \mathrm{Paz}$, en donde se casó, hacia 1590 , con la rica y atractiva viuda del encomendero Juan Remón, de cuyas conversaciones "nació la Miscelánea Austral escrita para celebrar la felicidad de su condición y estado" (pág. 70). El capítulo cuarto (págs. 72-84) trata de la nueva vida como encomendero-feudatario de Dávalos casado y de su actitud hacia los pobres indios que "casi no tenían alma". Hasta aquí se trata de capítulos preliminares (biográficos y descriptivos del contexto en que Dávalos actuó), siempre interesantes y llevados con mano ágil y segura, salvo, tal vez, cierta desproporción en su economia interna: así, por ejemplo, en el cap. III, dedicado a la estadía de Dávalos en La Paz, de las 18 páginas que lo integran, por lo menos diez tratan del capitán Juan Remón, que fue el primer esposo de la mujer del ecijano y que interesa sólo marginalmente el argumento (pero, después de tantas páginas, que arriesgan desviar nuestra atención del asunto principal, hay que reconocer que la autora nos compensa con creces, en las págs. $66-67$, con su magistral análisis del citado poema de Cilena, el cual encabeza la Miscelánea Austral).

A partir del capitulo quinto ("La Miscelánea Austral"), se entra de lleno en el asunto principal del libro, que es el de mostrar y demostrar el petrarquismo de Dávalos y sus modalidades.

Ante todo, demuestra, 'limitándose exclusivamente a pruebas textuales' (pág. 89), la unidad de la obra de Dávalos, en el sentido de que "la Defensa de Damas, largo poema que había sido considerado la segunda obra de Dávalos", en realidad "forma parte integral de la Miscelánea por estructura e intención" como ya lo había señalado "con lucidez" Luis Jaime Cisneros (apud id., ib.); pero los datos presentados por este filólogo "como corroboración de la unidad propugnada [...] resultan en exceso vagos, imprecisos e incompletos" (ib.). Nuestra autora, en cambio, halla las "pruebas [...] dentro de la misma Miscelánea" (págs. 90 y sigs.).

Aclarado este punto, puntualiza cómo 'el espíritu que informa la Miscelánea no es otro que el del neoplatonismo petrarquista del Cinquecento italiano. Un neoplatonismo que en Dávalos se atenúa de filosofía y se acuña en cortesanía” (pág. 99); y cómo "El núcleo de los coloquios amorosos de la Miscelánea Austral depende, efectivamente, de [...] el Libro de natura d'amo- 
re de Mario Equícola" (pág. 101). Más adelante, completa su pensamiento y agrega que "gran parte de la Miscelánea no sólo depende de ella [la obra de Equícola], sino que es una taracea de traducciones literales de la enciclopedia amorosa de Mario Equícola" (pág. 102). En efecto, por los dos fragmentos que presenta para su cotejo, se confirma que Dávalos ha traducido literalmente, palabra por palabra, a Equícola. Su habilidad se limita a 'montar cada fragmento en un nuevo texto en que el tratado se hace coloquio' (pág. 103). En suma, la A. nos demuestra fehacientemente que

toda esta sabiduría medieval de nuestro encomendero es absolutamente de segunda mano (pág. 105), [...] todo lo dicho con respecto a los poetas medievales puede repetirse con las citas infinitas de los clásicos (pág. 106).

Al respecto, nos ofrece las pruebas, en las págs. 108 y sigs., de que no sólo Equícola fue utilizado por Dávalos, sino también otros autores italianos como Orazio Rinaldi (Specchio di Scienze et Compendio delle Cose..., Venecia, 1583) e Yeronimo Ruscelli (Le Imprese Illustri..., Venecia, 1572); y agrega que

En todos los casos la traducción es textual y selectiva, recombinando muy a menudo la lista de definiciones que da Rinaldi, cambiando su orden, tomando algunas, dejando de lado otras (pág. 108). [...] No siempre Dávalos oculta tan cuidadosamente sus fuentes, pero aun cuando las nombra lo hace escondiéndolas entre un maremagnum de citas, de modo tal que pareciera que su texto principal -y del cual provienen las otras alusiones- es una cita más entre las muchas (pág. 111).

Ahora la A. nos ofrece una sugestiva página, nutrida de observaciones penetrantes, en la cual trata de ensimismarse con los motivos sicológicos y humanos, amén de literarios, que justificarían la imitación davaliana frente a los textos humanistas. Justamente por lo sugestiva merece transcribirse entera :

La necesidad de parecer culto fue endémica tanto en la admirada Italia como en nuestra lengua. Ejemplo estupendo es el mismo Fénix de los ingenios, que hacia la época en que Dávalos estaría comenzando su Miscelánea, usaba tipos de compendios semejantes al de Rinaldi para maravillar con la erudición de su Arcadia. Y si todo lo que es "de Lope" era el summum bonum ¿por que ha de criticarse la práctica en Dávalos? El deseo de parecer sabio acuciaba al escritor del siglo XvI en una Europa donde no podf́a caberle duda alguna de formar parte de una tradición y de una patria intelectual, zcómo no habrian de intensificarse estos sentimientos cuando se vivía en las Indias, sintíndose exilado de la tierra nativa y de los centros culturales de Occidente? La exhibición erudita del Cinquecento italiano declara la necesidad de incorporarse los clásicos porque sentfa el abismo entre su mundo y el propio 
ya desde Petrarca. Al sentido de pérdida de un pasado cultural se unió un resquemor de inferioridad en el presente, y así el texto humanista -que intenta revivir e incorporar a sf mismo los textos de la cultura admirada- es un intento de salvar el abismo entre ambos mundos. Júzguese entonces cómo serfa de acuciante esa nostalgia y ese sentimiento de inferioridad para un hombre en las circunstancias de Dávalos. Equícola y Rinaldi, con sus citas ad infinitum le devolvían la patria común de la respublica clericorum. Al incorporarlos - traducidos y recompuestos en su selección- Dávalos se incorporaba a si mismo ciudadano de la única patria que ya podía tener. Cuanto más fiel la traducción, mayor la seguridad de merecer esa carta de ciudadanf́a que le exigió la ansiedad y la nostalgia en el exilio indiano (pág. 111).

A este punto se pregunta, con harta razón: “¿Es Dávalos un plagiario?” (pág. 114). Y concluye que aunque "en el siglo xvi [...] el concepto de plagio existía, como lo demostraron las innumerables quejas de los que se sentian infamemente robados [...]. En realidad, Dávalos no plagia [...]. Lo que hizo $[\ldots]$ fue tomar de preferencia tratados y compilaciones no dialógicas y darles forma de coloquio" (págs. 114-115).

La tesis de la A. es que los personajes-interlocutores, Delio y Cilena, “aunque representan a Diego Dávalos y doña Francisca, no lo son" (págs. 115), $y$

Por tanto, Dávalos, el autor, no plagia sus fuentes. Sus interlocutores, personajes creados por el poeta, hacen suyas palabras en la supuesta ignorancia - la aparente sabidurfa que les exige su papel en la comedia dialógica” (pág. 116). «Por tanto, el diálogo ofrecía la excusa suprema para el más deslumbrante despliegue de erudición sin requerirla del autor, prestándole las máscaras de sus protagonistas para volcar tanto la sabidurfa propia como la ajena, y crear con ambas $-y$ hasta con la misma ignorancia - el poema dialogal. [...] La erudición era parte de esa hermenéutica esencial. Cada una de las citas de Equifcola y de las citas que citan Equifola y Ruscelli y Rinaldi, son imágenes de eso que el diálogo imita, son espejos y émulos de las cosas mismas, y, en suma, son todos un texto único (pág. 116).

La A. reanuda este tema de la ausencia de plagio en los capítulos séptimo y octavo sobre "Petrarquismo" (págs. 138 y sigs.) e "Imitación" (págs. 168 y sigs.), y es justamente en el primero en donde se pueden encontrar, dentro de la conocida y difundida poética de la imitatio, motivos suficientes como para no dejarme del todo convencido acerca de la tesis citada de que "Dávalos, el autor, no plagia sus fuentes". Ante todo, la distinción entre el autor y sus personajes no lo exenta necesariamente, de por sí misma, de la acusación de plagio, puesto que, ya se sabe, aquél habla por intermedio de éstos. En segundo lugar, no podemos suponer que el propio Dávalos se considere a sí mismo del todo exento de la acusación de plagio ("hurto") por el mero hecho de que "la poética que regía todo el Renacimiento fue la de 
la imitación" (pág. 140). En efecto, Dávalos de alguna manera tiene conciencia de la distinción entre lo que es tópico poético (que, como lo dice la A., pág. 146, "habiendo sido repetido mil veces, se vuelve propiedad común y despersonalizada, convención ahistórica, éjido poético") y lo que es "imitación o hurto", puesto que, ante la afirmación de Cilena de que cierto soneto suyo "encuentra como fuente el bien conocido de Petrarca «Amor, Fortuna e la mia mente schiva»", contesta que "no era tal el caso, porque «no devía de pensar y no pensava si no en quien alimenta el alma [es decir, la amada], aunque haya alguna similitud en mi concepto al de Petrarca, porque no todos los pensamientos que se encuentran son imitación o hurto [el subrayado es mío], pues es posible $y$ aun fácil ofrecerse a dos ingenios un mismo pensamiento, como cada dia se verifica» (XV, 58a)" (ib.).

En efecto, el soneto en cuestión no puede considerarse "hurto", ya que no representa una mera imitación mecánica (ni, mucho menos, simple traducción literal, como en otros numerosos casos), sino una recreación, una transformación del modelo (más aún, de los modelos, puesto que en él está presente también el soneto IV de Garcilaso) en algo nuevo y personal, en base a lo que el mismo Petrarca auspiciaba (y que Dávalos no podia ignorar...): " «Cuidad que el néctar no quede en vosotros en el mismo estado que cuando lo recogísteis, pues no tendrían gloria alguna las abejas si no lo transformasen en algo distinto y mejor. Por eso, si al leer o reflexionar halláis algo valioso, tornadlo en miel gracias al estilo vuestro» (Fam., I.8)" (pág. 143).

No deja de llamar la atención, pues (aun teniendo en cuenta la constante práctica de la imitatio renacentista y el distinto valor que se le daba en aquel entonces) el hecho de que Dávalos, a pesar de todo esto, se deje llevar, en gran parte de su Miscelánea Austral, por lo que él mismo llama "imitación o hurto": imitación las pocas veces que cita las fuentes de su reproducción textual y hurto las muchas que no las cita. ("A veces nombra su fuente, las más la oculta bajo el cúmulo erudito que la propia fuente le ofrece", pág. 112). Ya hemos visto más arriba que la distinción entre el autor y sus personajes dialógicos no es muy convincente como justificación. Así como no lo es del todo el hecho de que "el mismo Lope [...] usaba tipos de compendios semejantes al de Rinaldi [al que imitó textualmente Dávalos] para maravillar con la erudición de su Arcadia" (pág. 111). Tampoco puede ser atenuante como lo insinúa la A. (ib.) el hecho de que Dávalos "vivía en las Indias sintiéndose exilado de la tierra nativa y de los centros culturales de occidente". En realidad, habrá que reconocer que Dávalos, con todas las atenuantes que se quiera reconocerle (las peculiares de la época, las peculiares del género dialógico de entonces que 'permitía una gran libertad en la apropiación de materiales ajenos', las peculiares de su condición de 
desterrado en aquel desierto cultural de La Paz del siglo xvi-Xvir...), no fue muy coherente ni con el criterio de imitatio-recreatio postulado por su maestro y modelo Petrarca, ni con su propio criterio (implicito en la cita que he dejado apuntada más arriba) de considerar "hurto" la imitación que no fuera tópico o casual. No olvidemos que en "la soledad de aquellos desiertos" de la América de entonces y en condiciones históricas, culturales y humanas análogas, actuaron otros poetas como Hernando Domínguez Camargo, del Nuevo Reino de Granada, gran imitador de Góngora, el cual, sin embargo, no ha imitado con "hurto" los materiales léxicos, icónicos y sonoros de su modelo, sino recreándolos, reinventándolos sub specie aeternitatis, como lo he documentado en mi Prólogo a la edición crítica de sus Obras (Caracas, Biblioteca Ayacucho, 1986, págs. IX-XCV).

Por otro lado, Dávalos sabía muy bien imitar-recreando, puesto que lo hizo egregiamente, por ejemplo, en el soneto citado por la A. en las págs. 146-147, el cual "ofrece verdaderamente una red intertextual harto compleja". La misma A. ha documentado en él no sólo la imitación de Petrarca, sino, a la vez, la de Garcilaso. Pero, si se quiere ahondar más tal documentación, se pueden hacer algunas comprobaciones aún más puntuales.

Transcribimos, pues, ante todo, los textos colacionados por la A. (subrayados míos):

\section{DAVALOS:}

Caybse de las manos mi esperança, y como su diamante es ya trocado en frágil vidrio, todo se ha quebrado dando de lleno en la desconfiança.

Triste de mí, quán áspera mudança vino a mi suerte y en mi dulce estado, pues de mi gloria vivo desterrado sin esperar en mi dolor bonança.

$(\mathrm{XV}, 57 \mathrm{~b})$

PETRARCA:

Lasso, non di diamante ma d'un vetro veggio di man cadermi ogni speranza, e tutti miei pensier romper nel mezzow.

$(\mathrm{XV}, 58 \mathrm{a})$

\section{GARCILASO:}

Un rato se levanta mi esperanza tan cansada de haberse levantado torna a caer, que deja, mal mi grado, libre el lugar a la descontianza. 
¿Quién sufrirá tan áspera mudanza del bien al mal? ¡Oh, corazón cansado! esfuerza en la miseria de tu estado, que tras fortuna suele haber bonanza.

(Soneto IV)

$\mathrm{Y}$ veamos ahora cuáles son los elementos comunes:

Elementos comunes a Dávalos y Petrarca:

"Cayóse de las manos mi esperanza" y "di man cadermi ogni speranza"; "diamante > vidrio" y "diamante > vetro"; " quebrado-de lleno" y "romper-nel mezzo".

\title{
Elementos comunes a Dávalos y Garcilaso:
}

"Cayóse $[\ldots]$ mi esperanza" y "mi esperanza [...] torna a caer"; "dando de lleno en la desconfiança" y "libre el lugar a la desconfianza"; "[triste de mí] quán áspera mudança” y “¿ [Quién sufrirá] tan áspera mudanza?”, "dulce estado" y "bien"; "[ $\sin$ esperar en mi dolor] bonança" y "[tras fortuna suele haber] bonanza”.

Como se ve, los materiales verbales e icónicos cotejados son esencialmente los mismos, coincidiendo en parte con los de Petrarca y en parte con los de Garcilaso; pero Dávalos no se ha limitado aquí a una imitación literal e inerte, sino que los ha reelaborado partiendo ora de un modelo, ora de otro e inventándose así nuevas y originales totalidades poéticas. Aqui si podemos hablar tranquilamente de una imitación que dista mucho de ser plagio.

Otro ejemplo de imitación-recreación por parte de Dávalos, en relación con Petrarca, nos presenta y comenta ampliamente la A. en las págs. 164-167. Veámoslo:

\author{
DAVALOS: \\ Cantava yo de Amor de otra manera, \\ con versos dulces, tersos y limados, \\ sonantes, puros, graves y acordados, \\ fingiendo enojos, ansia y rabia fiera; \\ pero ya que la pena es verdadera \\ y que ausencia me colma de cuydados \\ van de todo primor tan apartados \\ quan llenos de verdad pura y sinzera. \\ ¡Qué mal se explica lo que bien se siente! \\ Y la pena a que el alma está rendida \\ mal la puede esmaltar el lastimado.
}


PETRARCA:

Pero ch'Amor mi sforza

et di saver mi spoglia,

parlo in rime aspre, et di dolcezza ignude

Dolci rime leggiadre

che nel primiero assalto

d'Amor usai, quand'io non ebbi altr'arme,

chi verrá mai che squadre

questo mio cor di smalto

ch'almen, com'io solea, possa sfogarme?

(Canzoniere, CXXV)

La A., en su hermoso y dilatado comentario, observa cómo

Ha recordado Dávalos tan bien la canción de Petrarca —antes rimas de amor dulces y pulidas, ahora ásperos versos sin primor-, que incluso preserva un eco del "smalto", pero mediatizado en su significación garcilasiana. [...] Dávalos parte de estas mismas premisas, pero [...] subvierte la raíz y esencia de la práctica petrarquista: la dulzura pasada no manifestaba, sino que fingía un mundo sentimental (pág. 165).

A sus acertadas observaciones podemos agregar aqui el cotejo textual de los elementos comunes entre los dos poemas: "parlo in rime aspre et di dolcezza ignude" y "[mis versos] van de todo primor tan apartados"; "Dolci rime leggiadre / che nel primiero assalto / d'Amor usai" y "Cantava yo de Amor de otra manera; / con versos dulces, tersos y limados"; "chi verrá mai che squadre / questo mio cor di smalto" y "la pena [...] / mal la puede esmaltar el lastimado".

También de este cotejo resulta claramente cómo Dávalos sabe muy bien imitar recreando, con gran soltura (y altura), bien lejos de aquella repetición inerte que caracteriza gran parte de su Miscelánea Austral.

En el capítulo Imitación, la A. llama oportunamente la atención sobre "el cuidado que se necesita antes de establecer filiaciones directas en un tipo de poesia basado en la imitatio" (pág. 176), debiéndose tener en cuenta que muchas imágenes renacentistas empleadas por Dávalos y demás ya eran tópicas,

lugares comunes del petrarquismo [...] propiedad que la convención ha hecho de todos, y asf́ pertenencia de nadie en particular. Por eso al encontrar un verso como "Lágrimas que aumentáis el mar undoso" no es inútil recordar el del soneto de Petrarca "fiume che spesso del mio pianger cresci" (CCCI), porque éste fue indudablemente el lugar originario, y todavfa no lugar común, de todos los desbordados llantos del petrarquismo. Pero pensar que tal fue 
necesariamente la fuente literaria de Dávalos es olvidar la fuerza y la inercia de una lengua poética comunitaria y hegemónica (pág. 173).

Al respecto, transcribe el soneto de Dávalos nutrido de "tópicos reiterados hasta la anonimidad" (pág. 172), que empieza así :

Lágrimas que aumentáis el mar ondoso,

suspiros, que crescéis el vago viento,

solloços, donde habita el descontento,

ansias, en quien jamás hallo reposo.

y que ella coteja con estos versos de Petrarca:

Piovonmi amare lagrime dal viso con un vento angoscioso di sospiri.

(Canzoniere, XVII)

los que, sin embargo, no representan necesariamente la fuente literaria directa del poema de Dávalos "denso entramado de lugares comunes [tópicos]" (pág. 173). Con todo, la misma A. se pregunta, en seguida: “¿Dónde acaban los tópicos y dónde habita el modelo?” (pág. 174). A este punto, hasta podriamos preguntarnos si el verso de Dávalos que se acaba de citar sea sólo tópico o si acaso no represente aquí, a pesar de su posible topicidad, una filiación directa, puesto que se coloca en un contexto de imágenes que reproduce, en su conjunto y orgánicamente, casi todos los materiales icónicos de los dos versos de Petrarca cotejados por la misma A. (los elementos comunes o equivalentes son: "Piovonmi" y "mar"; "amare" y "descontento"; "lagrime" y "lágrimas"; "vento" y "viento"; "angoscioso" y "ansias" ; "sospiri" y "suspiros").

Al ponernos en guardia la A. también sobre el hecho de que "varios pueden haber leído un mismo poema y hacerlo subtexto de los propios, sin necesidad, por tanto, de ninguna filiación directa" (pág. 174), nos ofrece el ejemplo de un soneto de Dávalos que bien parece imitado de uno de Hernando Acuña y demuestra que, en cambio, ambos imitaron posiblemente, "de muy cerca, pero sin dependencia mutua alguna", un soneto de Giovanni Mozzarello. Por el cotejo de los tres sonetos que la A. transcribe, las semejanzas son asombrosas. Creo que se puede hablar, tanto para Acuña como para Dávalos, de verdadera traducción libre. Se podría agregar que, mientras el primero traduce casi todos los versos de Petrarca uno por uno, Dávalos traduce sólo una parte de aquéllos a la vez que sustituye los demás por otros versos semánticamente ajenos al modelo. Es una técnica de imitatio en que se alternan versos imitados de un autor con versos no-imitados (¿o imitados de otro autor? Es un tema que, tal vez, merecería profundizarse). 
De todos modos, el comentario literario comparativo entre el texto de Acuña y el de Dávalos que, en este punto, la A. nos ofrece, resulta de lo más interesante a pesar de que a mí el citado soneto de Acuña no me parece tan malo. Sin poner en tela de juicio la superioridad global del de Dávalos, diría que en ambos sonetos se alternan versos bien logrados con otros menos logrados. Por ejemplo, me parece tan notable en Acuña la primera estrofa ("Mientras de parte en parte se abrasava / y en bibas llamas la gran Roma ardía ; / al alto cielo el clamor subía / del pueblo todo que su mal lloraba”) así como en Dávalos la tercera ("Solo canta Nerón subido en parte / do no siente del vulgo las querellas, / celebrando las llamas y centellas / que licenciosas van por toda parte).

Finalmente, al hablar del concepto de "traducción" en Dávalos, para el cual "traducir es pelear en lugar estrecho y peligroso, que no permite echar passo atrás ni adelante, aunque sea para mejorarse, lo que no tiene el componer" (lo cual indica que el mismo aboga por un criterio restrictivo y literal), la A. aclara, con toda razón, que "a veces ni hasta el mismo puede marcar claramente los lindes entre traducción e imitación, entre el trasladar y el componer" (pág. 185). Se podría agregar que es hasta objetivamente difícil establecer un limite neto, dentro de la práctica de la imitatio, entre traducción y composición. En efecto, la traducción libre, dentro de dicha práctica, puede considerarse como una cosa y otra a la vez.

De todos modos, la misma A. transcribe los versos de Dávalos por la muerte de su hermana, en los cuales ya no se puede hablar de traducción, sino de imitación. Y agrega que "no salió la suya particularmente afortunada, como si, en efecto, el dolor le hubiese ofuscado el ingenio" (pág. 185).

Los límites materiales de esta nota no me permiten transcribirlos todos y analizar como quisiera el nutrido y penetrante comentario de la A. Tan sólo puedo adelantar que tampoco los versos de Dávalos me parecen tan deleznables si parva maximis comparari licet. Por supuesto que no podemos compararlo con Petrarca midiéndolo con el mismo metro...

Aqui hay que interrumpir, pues, estas reflexiones sobre el libro de Alicia Colombi Monguió. Claro está que, como todos los trabajos humanos, éste tampoco deja de tener sus luces y sus sombras (y sus penumbras, como las que he dejado apuntado), pero está claro también que las sombras son las que justamente nos permiten apreciar mejor, por contraste, las luces.

Para concluir, no me queda sino celebrarlo como una de las obras más serias y originales y, a la vez, más cautivantes (a pesar de su carácter eminentemente erudito) dentro de la crítica literaria hispanoamericana de los siglos XVI y xvir. 